\title{
Research Paper \\ Effect of Combined Exercise and Ginkgo Biloba Supplementation for 8 Weeks on Brain-derived Neurotrophic Factor Level in Depressed Older Men
}

\author{
${ }^{*}$ Bahman Hasanvand ${ }^{1}(1)$, Alireza Farhadi ${ }^{1}$ (1)
}

1. Department of Physical Education, Faculty of Humanities, Khorramabad Branch, Islamic Azad University, Iran.

\begin{tabular}{|l|l|l|l|l}
\hline $\begin{array}{c}\text { Use your device to scan } \\
\text { and read the article online }\end{array}$ & $\begin{array}{l}\text { Citation: Hasanvand B, Farhadi A. [Effect of Combined Exercise and Ginkgo Biloba Supplementation for } 8 \text { Weeks on Brain- } \\
\text { derived Neurotrophic Factor Level in Depressed Older Men (Persian)]. Iranian Journal of Ageing. 2021; 16(2):234-247. https:// } \\
\text { doi.org/10.32598/sija.16.2.2805.1 }\end{array}$ \\
doi https://doi.org/10.32598/sija.16.2.2805.1
\end{tabular}

\section{(i) (8)}

Received: 05 Sep 2019 Accepted: 29 Nov 2020 Available Online: $01 \mathrm{Jul} 2021$

Key words: Brain-derived neurotrophic factor Combined exercise, Ginkgo biloba extract, Depression, Elderly

\section{ABSTRACT}

Objectives The current study aims to examine the effect of combined exercises and ginkgo biloba supplementation for 8 weeks on Brain-Derived Neurotrophic Factor (BDNF) level in depressed older men. Methods \& Materials Forty depressed older men were randomly divided into four groups of exercise $(n=10)$, supplementation $(n=10)$, exercise + supplementation $(n=10)$, and control $(n=10)$. In the pre-test phase, blood samples were taken from the subjects. Then the participants in the exercise group performed combined exercises for eight weeks, 3 sessions per week. Those in the supplementation group, the subjects were given $80 \mathrm{mg}$ of ginkgo biloba extract daily for eight weeks. In the exercise + supplementation group, the subjects received both interventions simultaneously. Blood samples were taken again 24 hours after the end of intervention. Collected data were analyzed using paired t-test, one-way ANOVA, and Bonferroni Post Hoc Test.

Results Eight weeks of combined exercise alone, ginkgo biloba supplementation alone, and combined exercise and ginkgo biloba supplementation simultaneously significantly increased BDNF level in depressed older men $(P<0.05)$. The increase in the BDNF level of subjects in the exercise + supplementation group was higher (84.78) compared to the exercise (74.37) and supplementation (72.20) groups.

Conclusion Simultaneous use of combined exercises and ginkgo biloba supplementation can be used by geriatricians to improve brain function of depressed older men.

\section{Extended Abstract}

\section{Introduction}

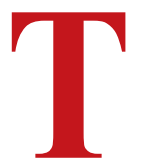

he aging process has been shown to reduce the functional capacity of the brain, learning ability, and spatial memory in old age [1]. Many studies have shown an association between low levels of brain-derived neurotrophic factor (BDNF) and depression in the elderly. Exercise can modulate levels of BDNF, but its effect on BDNF at baseline and after exercise is not clear [2]. Studies have shown that ginkgo biloba extract supplementation has neuroprotective effects and improves cognitive function capacity by increasing the concentration of BDNF $[3,4]$. This study aims to assess the simultaneous effect of 8 weeks of ginkgo biloba extract supplementation and combined exercise on BDNF level in depressed older men.

\section{Methods}

In this quasi-experimental study with a pre-test/post-test design, 40 depressed older men with mild severity (score 8 -15 in Beck Depression Inventory) were selected as study samples from an elder care center in Khorramabad, Iran. They were divided into 4 groups of combined exercise

\section{* Corresponding Author:}

Bahman Hasanvand

Address: Department of Physical Education, Faculty of Humanities, Khorramabad Branch, Islamic Azad University, Iran.

Tel: +98 (916) 6616983

E-mail: hasanvand121@gmail.com 
$(\mathrm{n}=10)$, supplementation $(\mathrm{n}=10)$, combined exercise + supplementation $(\mathrm{n}=10)$, and control $(\mathrm{n}=10)$. After selecting the samples, the working conditions and the study method were fully explained to them and they were assured that taking the supplement or performing exercises would not have any side effects for them. Blood sampling was done In the pre-test phase by a laboratory expert. BDNF levels were measured using a special kit. 24 hours later, in the combined exercise group, the subjects performed the exercise protocol for 8 weeks, 3 sessions per week [5]. In the supplementation group, the subjects consumed $80 \mathrm{mg}$ of ginkgo biloba extract daily for 8 weeks [6]. In the combined exercise + supplementation, subjects received both interventions simultaneously. During this period, the control group performed their daily activities and took a placebo. Blood sampling was again performed 24 hours after the end of intervention.

\section{Results}

The results of the present study showed that combined exercise had a significant effect on the level of BDNF in depressed older men $(\mathrm{t}=-3.204, \mathrm{P}=0.011)$. Their mean $\mathrm{BDNF}$ level increased from $68.54 \mathrm{Pg} / \mathrm{ml}$ at pre-test phase to 74.37 $\mathrm{Pg} / \mathrm{ml}$ at post-test phase. Ginkgo biloba extract supplementation also had a significant effect on the level of BDNF in subjects $(\mathrm{t}=-2.431, \mathrm{P}=0.038)$. Their mean BDNF level increased from $66.94 \mathrm{Pg} / \mathrm{ml}$ at pre-test phase to $72.20 \mathrm{Pg} /$ $\mathrm{ml}$ at post-test phase. The simultaneous use of combined exercise and ginkgo biloba extract supplementation also had a significant effect on the level of BDNF in older men $(\mathrm{t}=$ -14.578, $\mathrm{P}=0.001$ ). Their mean BDNF level increased from $70.55 \mathrm{Pg} / \mathrm{ml}$ at pre-test phase to $84.78 \mathrm{Pg} / \mathrm{ml}$ at post-test phase. In the control group, no significant difference was reported $(t=-0.840, P=0.423)$. There was a significant difference between the groups in terms of BDNF $(\mathrm{F}=21.825$, $\mathrm{P}=0.001)$. The results of Bonfrroni post hoc test showed that combined exercises plus ginkgo biloba supplementation increased BDNF by $9.262 \mathrm{Pg} / \mathrm{ml}$ compared to combined exercises alone; by $10.508 \mathrm{Pg} / \mathrm{ml}$ compared to supplementation alone; and by $19.606 \mathrm{Pg} / \mathrm{ml}$ compared to placebo $(\mathrm{P}<0.05)$. There was no difference between combined exercise and supplementation groups in BDNF level $(\mathrm{P}>0.05)$.

\section{Discussion and Conclusion}

Simultaneous use of combined exercises and ginkgo biloba supplementation for 8 weeks increases the levels of BDNF in depressed older men more than when combined exercises and ginkgo biloba supplementation are used alone. Specialists can use combined exercises along with ginkgo biloba extract supplementation to improve functional capacity of brain in in depressed older men.

\section{Ethical Considerations}

\section{Compliance with ethical guidelines}

All ethical principles are considered in this article. The participants were informed about the purpose of the research and its implementation stages. They were also assured about the confidentiality of their information and were free to leave the study whenever they wished, and if desired, the research results would be available to them.

Funding

This research did not receive any grant from funding agencies in the public, commercial, or non-profit sectors.

Authors' contributions

All authors equally contributed to preparing this article.

Conflicts of interest

The authors declared no conflict of interest. 
This Page Intentionally Left Blank 
(BDNF) تأثير هشت هفته تمرينات تركيبى و مكمل جينكوبيلوبا بر عامل نروتروفيك مشتق از مغز سالمندان مرد اقسرده هفته تمرينات

\author{
"بهمن حسنوند' (ه، عليرضا فرهادى'
}

ا. كروه تربيت بدنى، دانشكده علوم انسانى، واحد خرم آباد، دانشكاه آزاد اسلامى، ايران.

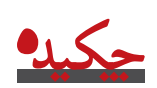

أهدافت مطالعه حاضر با هدف تأثير هشت هفته تمرينات تركيبى و مكمل جينكوبيلوبا بر عامل نروتروفيك مشتق از مغز سالمندان مرد

افسرده انجام كرفت.

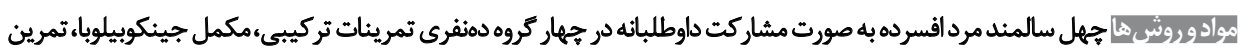

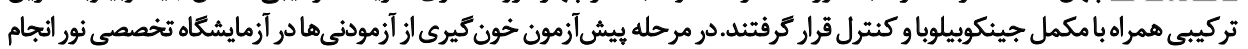

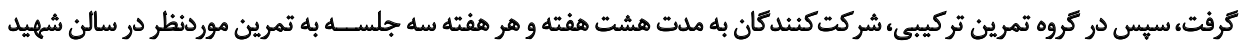

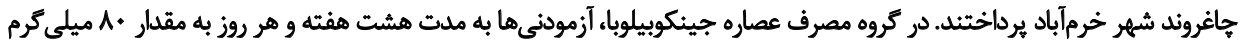

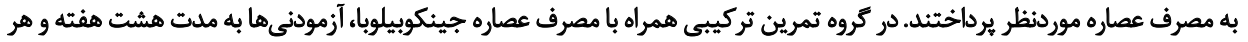

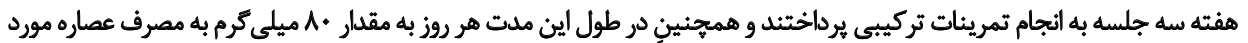

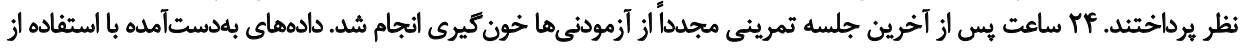

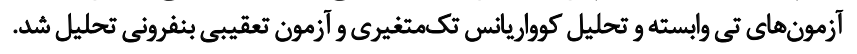

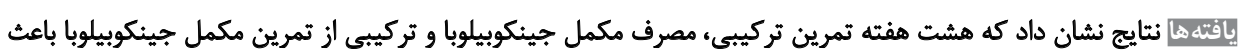

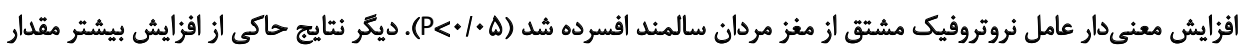

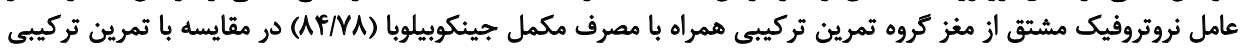
(VF/WV)

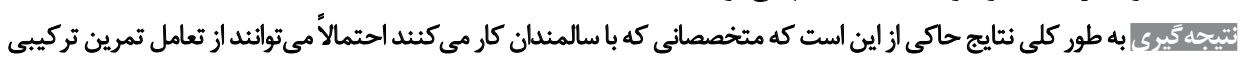

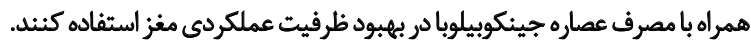

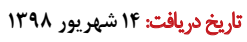

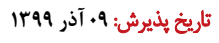
تاريخ انتشار: 9 آذر 999

طبق اين آمار ميتوان اظهار كرد كه ايران در شرايط فعلى در

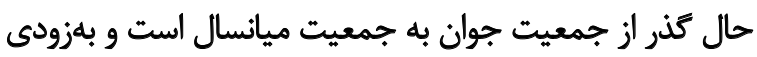

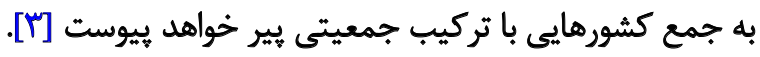

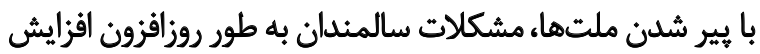

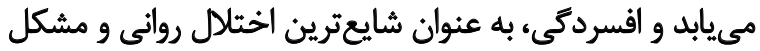

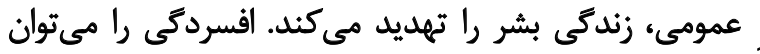

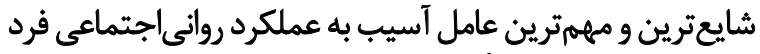

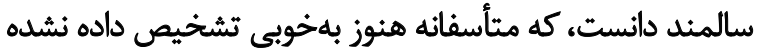

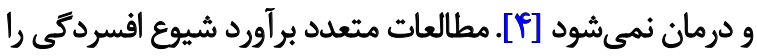

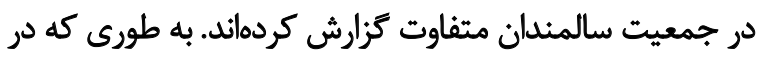

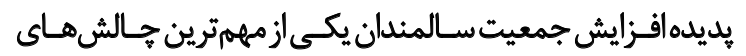

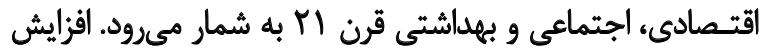

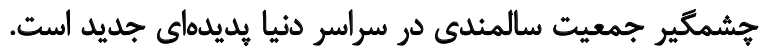

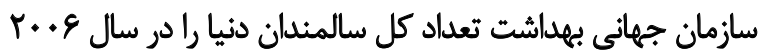

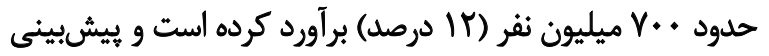

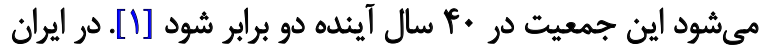

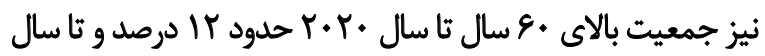

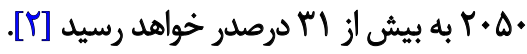

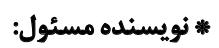

بهنمن حسنوند

نشانى: خرم آباد، دانشكاه آزاد اسلامى، واحد خرم آباد، دانشكده علوم انسانى، كروه تربيت بدنى. تلغن:

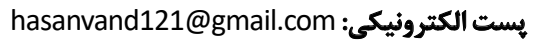


در مويركها هستند. مكانيسم عمل آنها به اين صورت است

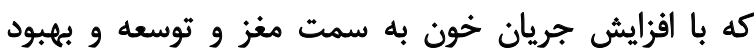

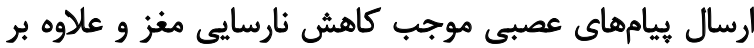

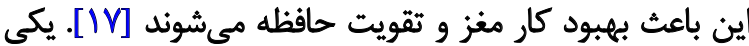

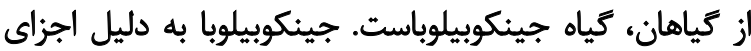

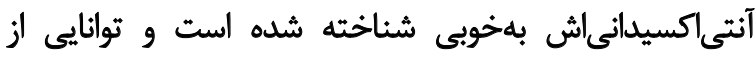

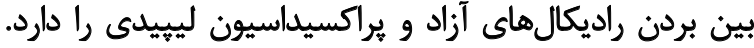

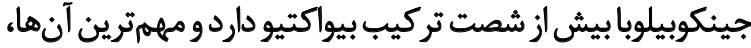

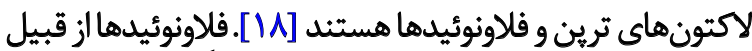

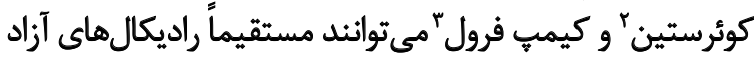

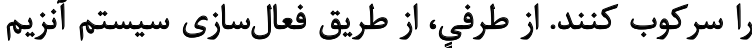

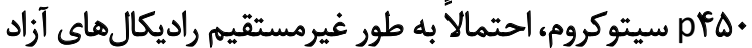

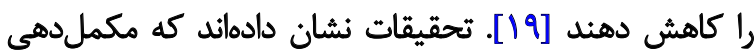

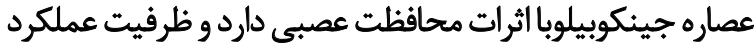

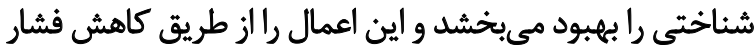

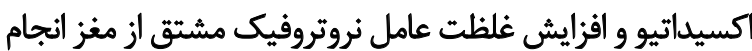

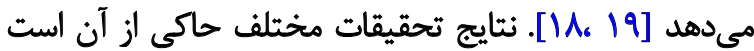

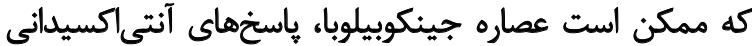

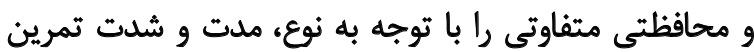

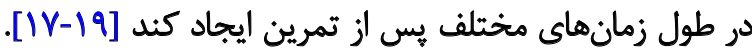

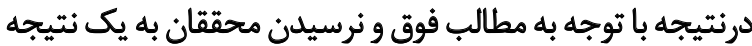

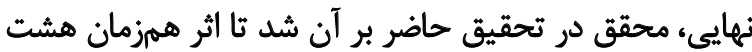

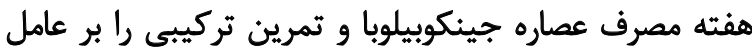

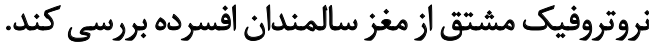

$$
\text { روش مطالعه }
$$

تحقيق حاضر از نوع تحقيقات نيمهتجربي است كه به صورت

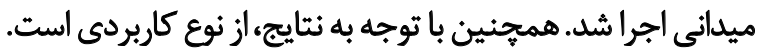

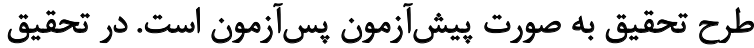

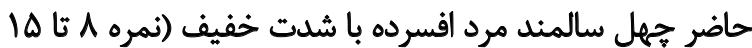

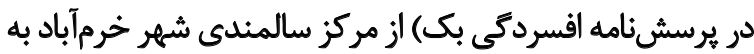

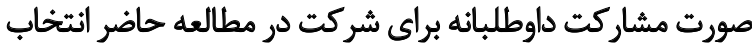

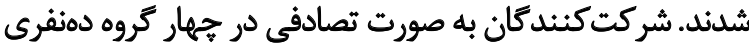

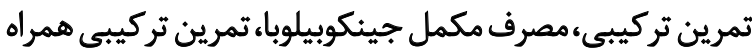

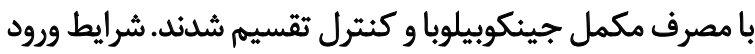

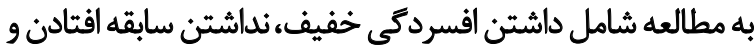

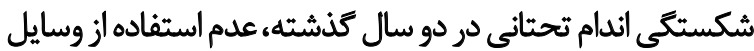

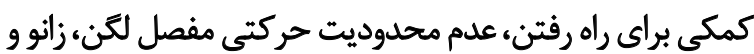

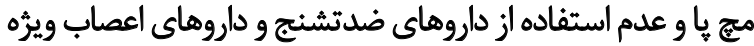

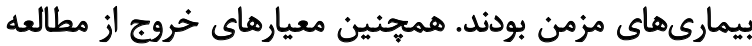

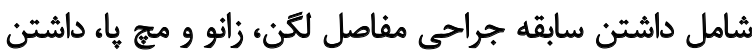

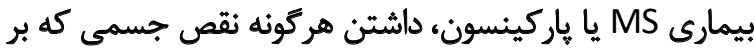

\section{Quercetin}

3. Kaempferol

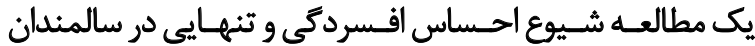

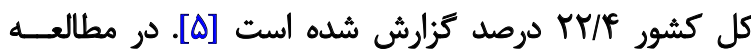

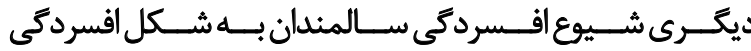

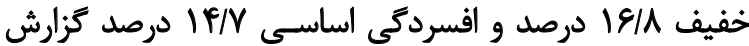

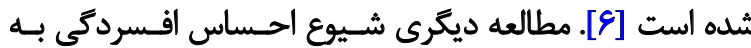

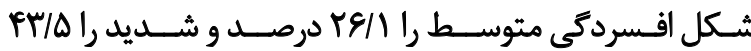

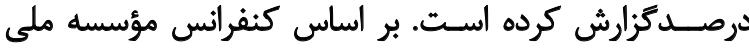

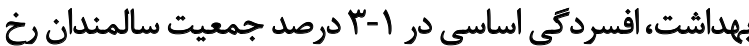

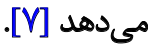

ثابت شده كه فرايند ييرى به كاهش ظرفيت مانيت عملكردى مغز

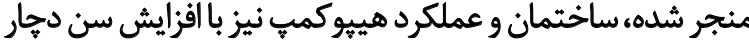

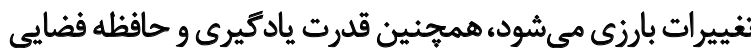

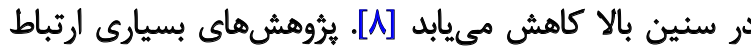

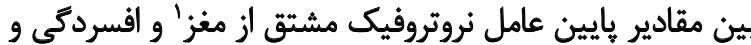

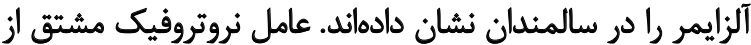

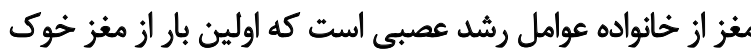

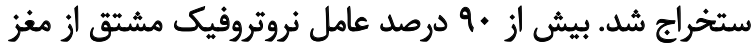

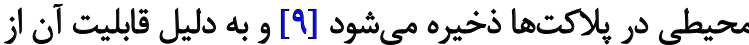

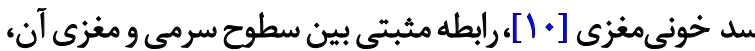

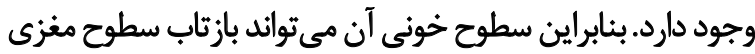

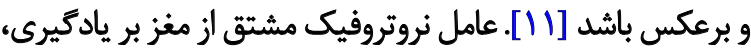

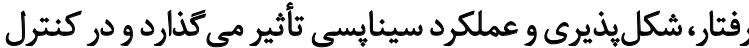

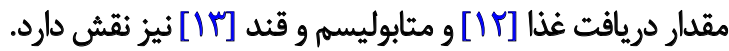
منبـع سـلولى عامل نروتروفيك مشتق از مغز در باســـخ

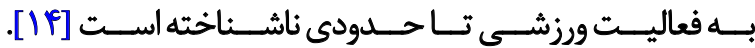

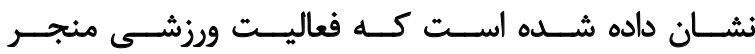

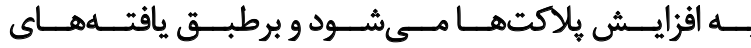

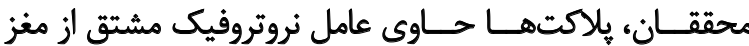

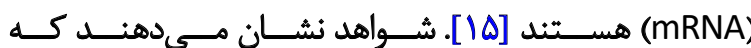

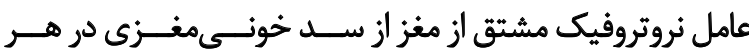

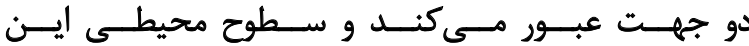

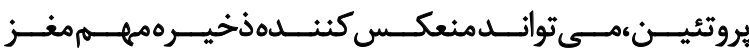

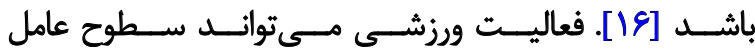

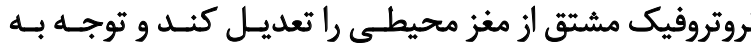

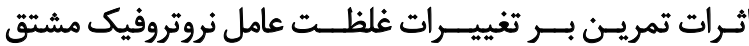

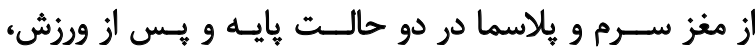

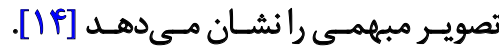

علاوه بر اثر فعاليت بدنى بر مغز، همجينين نشان داده شده

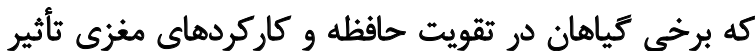

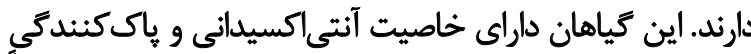

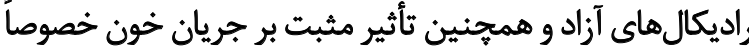


از مترنوارى بر حسب سانتىمتر جهت اندازهكيرى قد

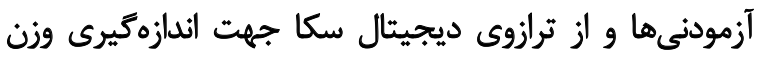
آزمودنى هـا استفاده شد.

از كيت الايزا، عامل نروتروفيك مشتق از مغز (ئر)

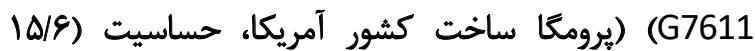

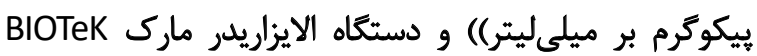
(Merck; Germany)

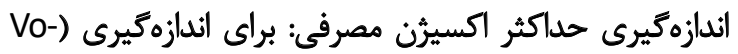

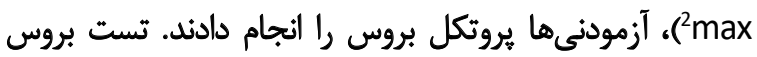

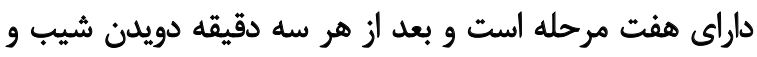

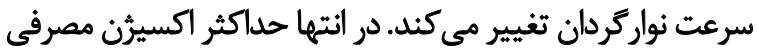
بر اساس فرمول مربوطه برآورد محاسبه شد شد. حداكثر قدرت بيشينه (RM1): براى اندازهكيرى قدرت بيشينه

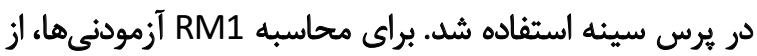
فرمول برزيكى" (فرمول شماره () استفاده شد:

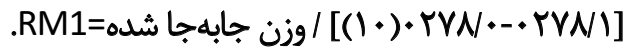
اين فرمول شيوه ايمن و مؤثرى براى تعيين RM1 است بدون بردين

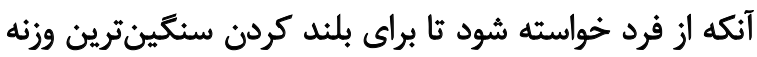

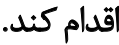

مكمل جينكوبيلوبا: در تحقيق حاضر مكمل جينكوبيلوبا به شكل

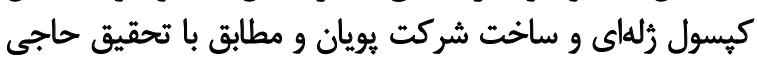

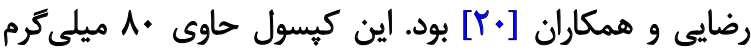

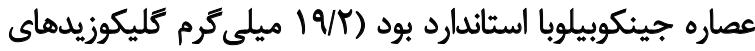

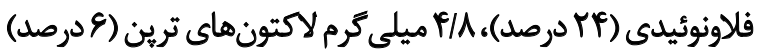

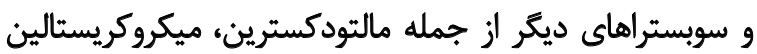

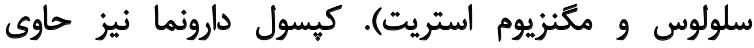
ميكروكريستالين سلولوس، مكُنزيوم استريت و مالتودكسترين بودي حارنما نيز

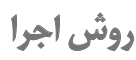

ابتدا با اعلام يك فراخوان از علاقهمندان به شركت در اين إندان

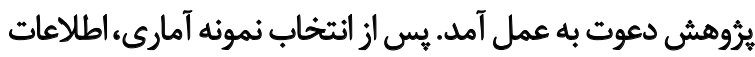

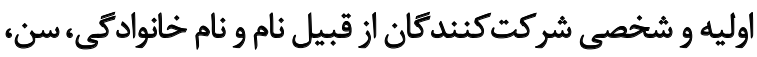

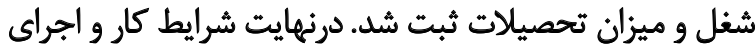

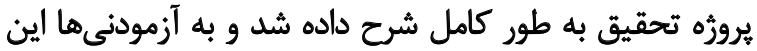

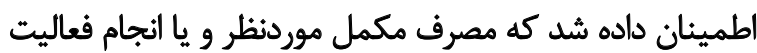
ورزشى عوارض جانبى براى آنان ندارد و حتى بـى براى سلى سلامتى آنان

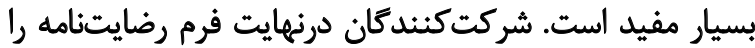

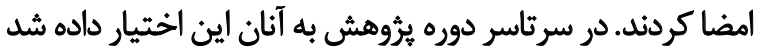

4. Brzycki

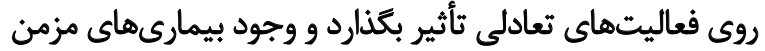

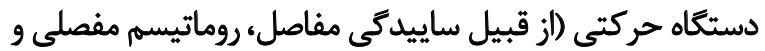

$$
\text { يوكى استخوان) بود. }
$$

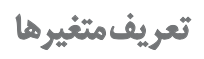

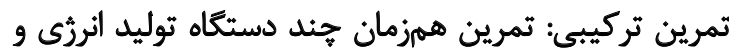

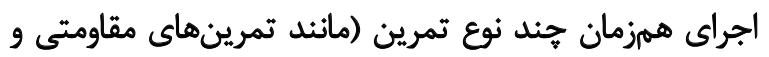

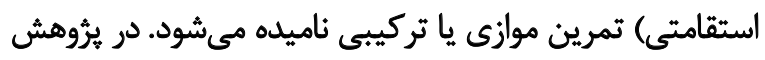

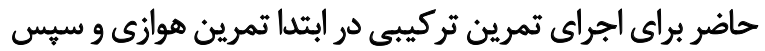

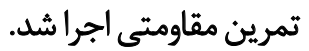

جينكوبيلوبا: جينكو يكى از قديمىترين تياهان آسيان آسيايى

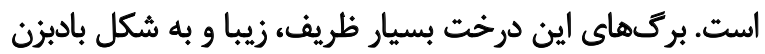

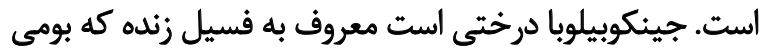

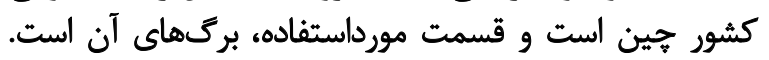

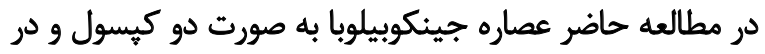

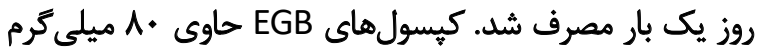

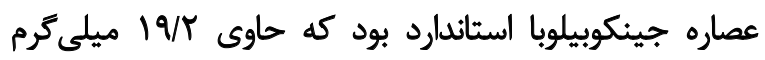

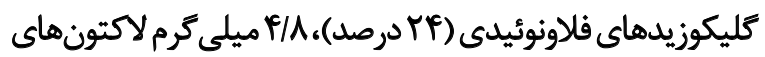
ترين (9 درصد) و سوبستراهاى ديكر از جمله مئه مالتودكسترين،

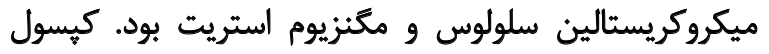
دارونما نيز حاوى ميكروكريستالين سلولوس و مكنين سلولوس، مكَنزيوم استريت بوديت

$$
\text { و مالتودكسترين بود. }
$$

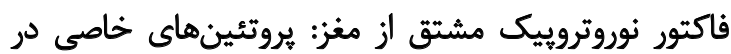

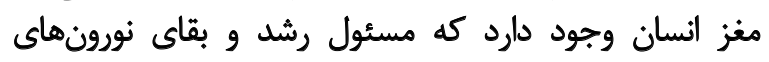

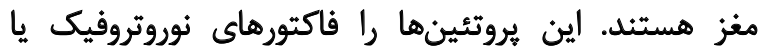

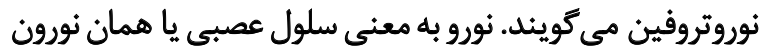

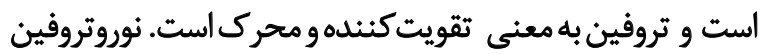

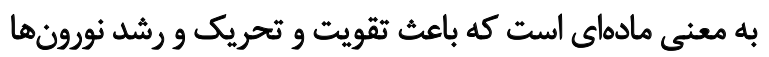

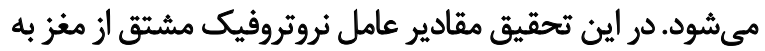

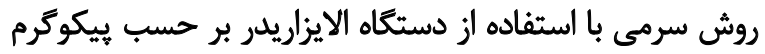

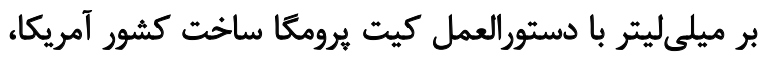

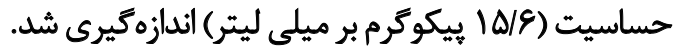

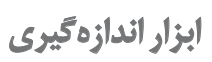

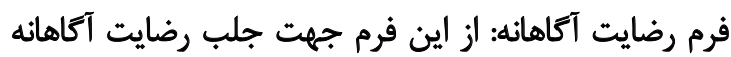
شركت كنندكان براى شركت در مطالعه حاضر استفاده شد.

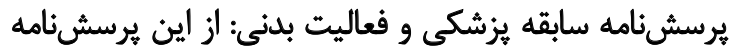

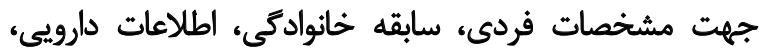

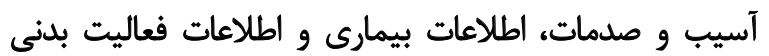
شركت كنندكان استفاده شد. يرسشنامه يادآمد رزيم غذايي: از اين يرسش ئامه جهت كنترل رزيم غذايى شركت كنئدكان استفاده شد. 
ب) تمرين مقاومتى: برنامه تمرين مقاومتى به مدت هشت

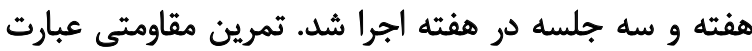

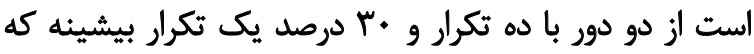

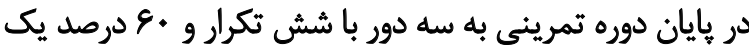

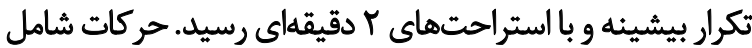

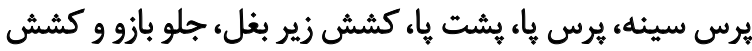

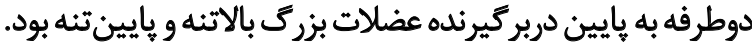

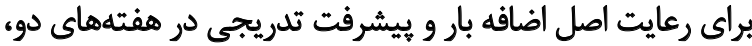

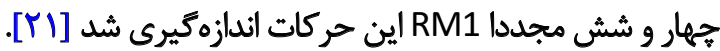

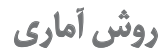

به منظور تجزيه و تحليل اطلاعات، از روشهاى آمار توصيفى

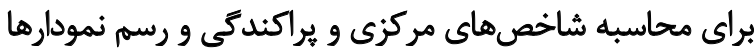

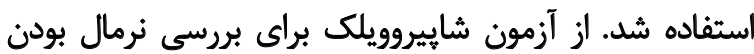

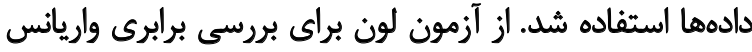

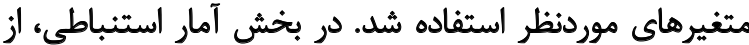

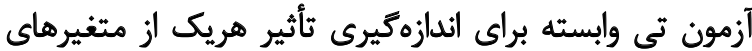

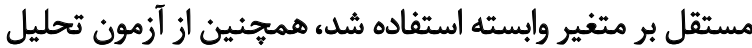
كوواريانس تكمتغيرى و آزمون تعقيبي بونفرونى براني براي مقايسه

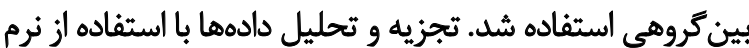

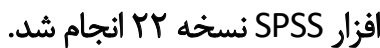

يافتهنا

ميائكين و اتحراف معيار شاخصهاى آنترويومترى آزمودنىها

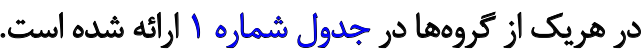

ميانكين و انحراف معيار مقدار عامل نروتروفيك مشتق از مغز

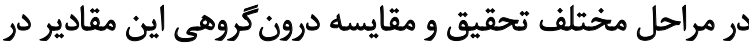

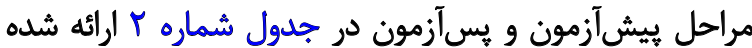

همانطور كه در جدول شماره Y مشاهده مي مشود تمرينات

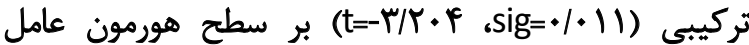

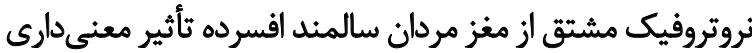

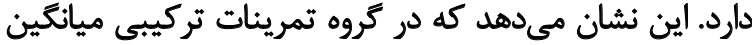

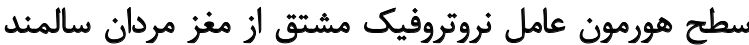

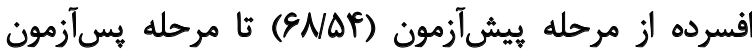

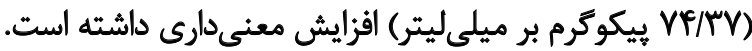

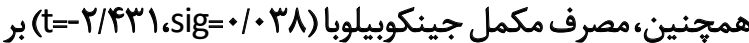

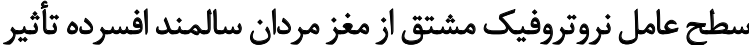

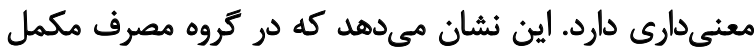

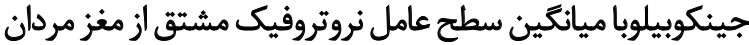

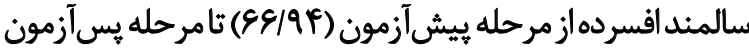

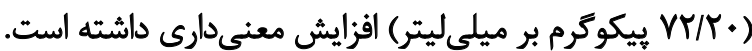

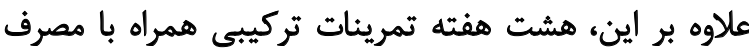

كه هر وقت و به هر دليلى قصد ترك مطالعه و لغو آن را داشته

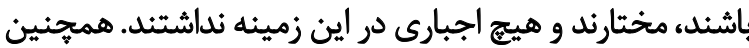
يروتكل تحقيق توسط كميته اخلاق دانشكاه علوميزشكى خرئ نرمآياد

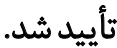

تحقيق شامل دو مرحله ييشآزمون و يسآزمون بود و در در

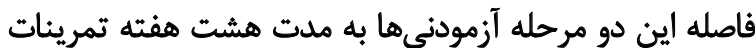

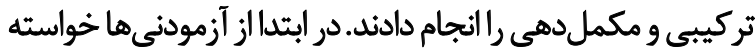

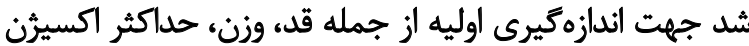

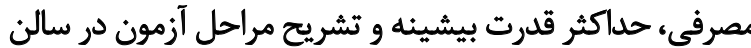

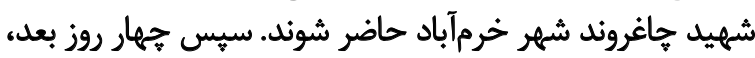

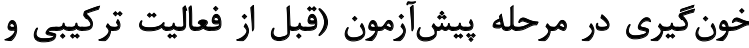

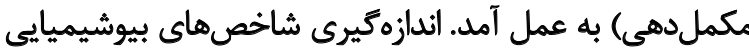

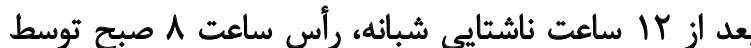

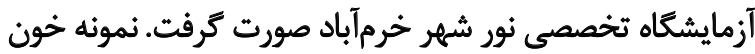

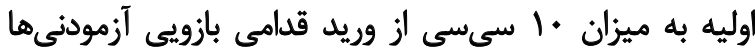

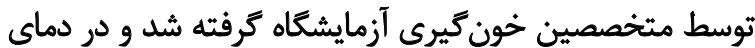

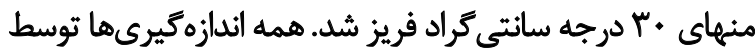

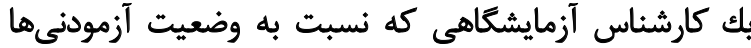

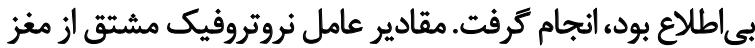

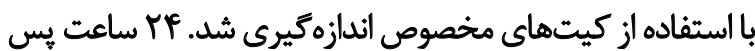

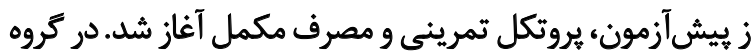

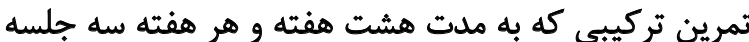

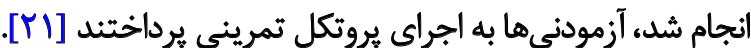

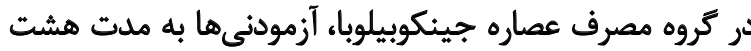

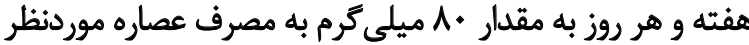

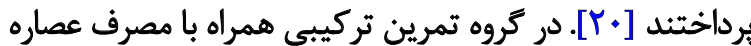

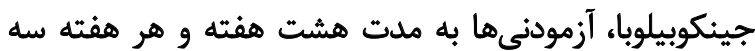

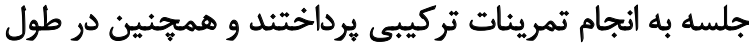

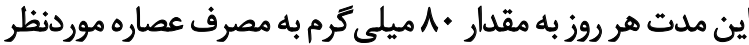

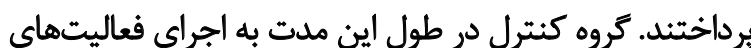

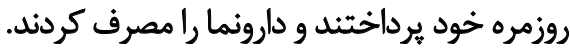

يروتكل تمرين تركيبي: اين هروتكل به مدت هشت هفته اجرا

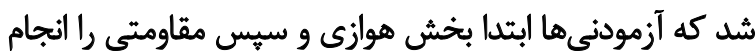
دادند.

الف) فعاليت هوازى: تمرين هوازى به مدت هشت هفته و سه

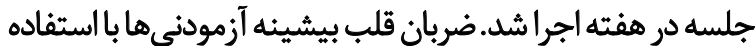

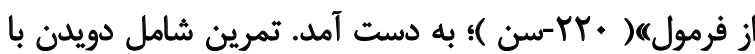

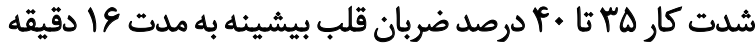

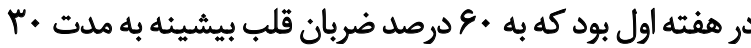

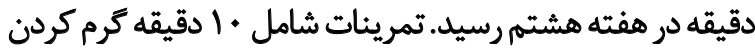

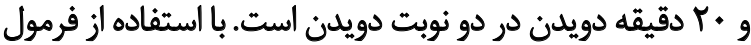

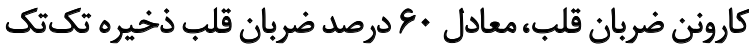
نفرات محاسبه شد و در اختيار آزمودنىها تحرئ تحقيق قرار كرفت 
جدول ا. ميانكين و انحراف معيار شاخصهاى آنترويومترى آزمودنىها

\begin{tabular}{|c|c|c|c|c|}
\hline وزن (كيلوكيرم) & قد (سائتىمتر) & سن (سال) & & \\
\hline$V \cdot / 1 \cdot \pm \psi(1)$ & $\mid q V / 1+ \pm r / . r$ & $s f / r+ \pm r / v$. & 1. & كنترل \\
\hline$V I / P+ \pm \Delta /{ }^{\prime} \wedge$ & $|F V / A \cdot \pm r / M|$ & 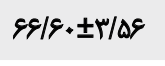 & 1. & تمرين تركييى \\
\hline$V T / r+ \pm \varphi r / r q$ & $1 V \cdot 1 \Delta \cdot \pm r / a T$ & $E M / Q+ \pm$ Y/RP & 1. & مكمل جينكوبيلوبا \\
\hline$n / \Delta \cdot \pm \Delta / R$ & $|\varepsilon q / r \cdot \pm r| \cdot q$ & gefr. \pm m/le & 1. & تمرين تركيبى+ مكمل جينكوبيلوبا \\
\hline
\end{tabular}

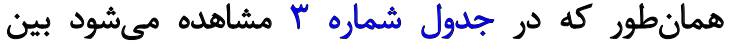

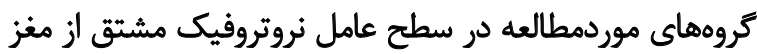

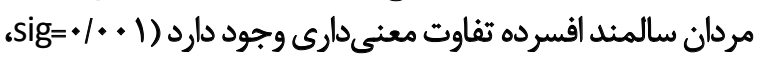
جيكوبي (F= Yl/ATA

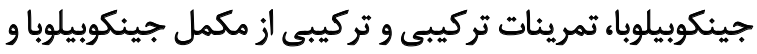

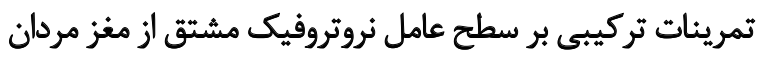

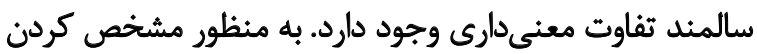

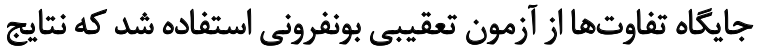
آن در جدول شماره fا ارائه شده است.

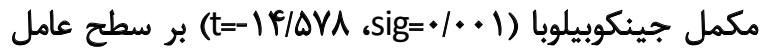

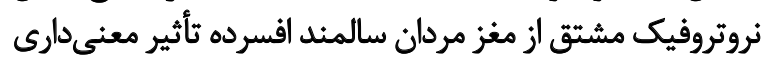

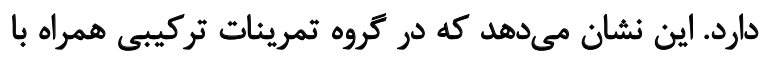

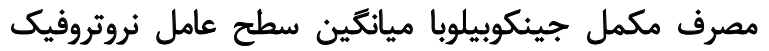

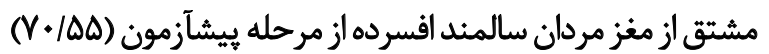

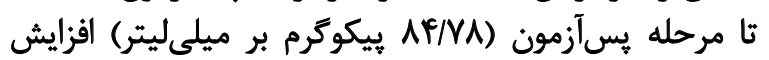

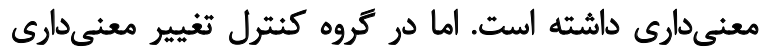

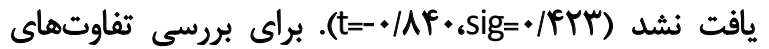

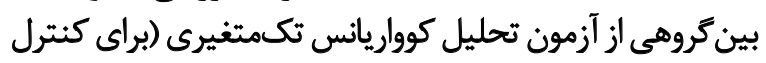

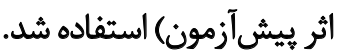

جدول r. ميانكين و انحراف معيار مقدار عامل نروتروفيك مشتق از مغز و نتايج آزمون تى وابسته در هريك از كروهها

\begin{tabular}{|c|c|c|c|c|c|}
\hline سطع معنى داري & آزادئ & $t$ & ميانكين||نحراف معيار & مرحله & كروه \\
\hline .1011 & 9 & $-r / T \cdot f$ & $\begin{array}{l}\text { ENQF } \pm F / M r \\
n^{E} / R V \pm T / \Delta\end{array}$ & يشيش آلزهون & تمرينات تركيبى \\
\hline I. & 9 & - T/MTI & $\begin{array}{l}E g / q r \pm g / \cdot r \\
V T / T \cdot \pm \Delta / 1 \Delta\end{array}$ & يبس آز بيسن & هكمل جينكوبيلوبا \\
\hline $.1 .+1$ & 9 & $-I f / \Delta V A$ & $\begin{array}{l}V \cdot / \Delta \Delta \pm \Delta / *+1 \\
A \leftarrow / V A \pm \% / / \% q \varphi\end{array}$ & بيش آلزمون & تمكل جينكوبيلوبا + \\
\hline TH & 9 &.$- / A F$. & $\begin{array}{l}\Delta V / F q \pm \& / g \Lambda \\
\Delta V / q \Psi T \pm V /+q\end{array}$ & بيش آزآمون & كتترل \\
\hline
\end{tabular}

跳

جدول س. نتايج تحليل كوواريائس براي مقايسه كروهها در سطح عامل نروتروفيك مشتق از مغز

\begin{tabular}{|c|c|c|c|c|c|c|}
\hline مجذور اتا & سطح معنى دارى & Fقدار F F F & ميانكين مجذورات & درجه آزادى & مجموع مجذورات & منيع تغييرات \\
\hline - MVO & $.1 \cdot+1$ & $m V \cdot 18$ & TEE/QHT & 1 & res/arr & بيش آزمون \\
\hline \multirow[t]{2}{*}{ - lear } & $.1 .+1$ & MVATA & $r \lambda+/ \varepsilon p q$ & $r$ & 1191/9m & يينكروهى \\
\hline & & & $\mid V / F+1$ & ro & $81 . / 17 t$ & خطا \\
\hline
\end{tabular}

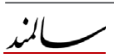


جدول F. نتايج آزمون تعقيبى بونقرونى به منظور مشخص كردن جايكاه تفاوت كروهها در عامل نروتروفيك مشتق از مغز

\begin{tabular}{|c|c|c|c|}
\hline سطح معنادارى & تفاوت ميانكين & كروه & \\
\hline$+1++1$ & $-1 \cdot / \pi+a$ & تمرينات تركيبى & \\
\hline.+1 & $-9 \cdot 94$ & مكمل جييكوبيلوبا & 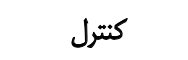 \\
\hline $.1 . .1$ & $-19 / 8.8$ & تمرينات تركيبي + مكمل جينكوبيلوبا & \\
\hline $1 / \cdots$ & $1 / \pi r V$ & مكمل جينكوبيلوبا & تمرينات تركييى \\
\hline $.1 \cdot+1$ & -qRer & تمرينات ثركيبي + مكمل جينكوبيلوبا & \\
\hline.$* 1$ & $-1 \cdot 10+1$ & تمرينات تركيبى + مكمل جييكوبيلوبا & مكمل جينكوبيلوبا \\
\hline
\end{tabular}

选

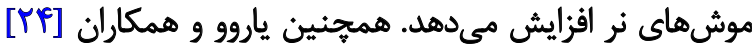

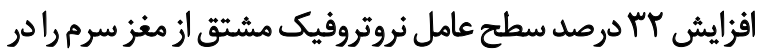

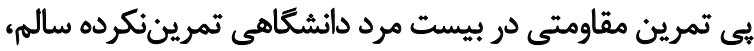

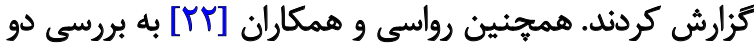

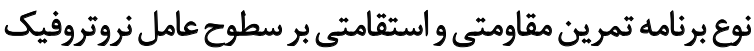

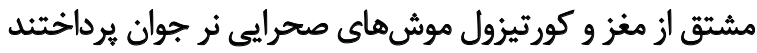

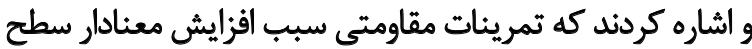

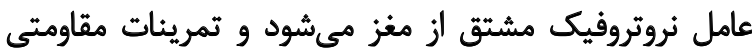

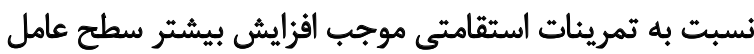

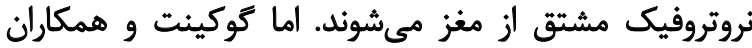

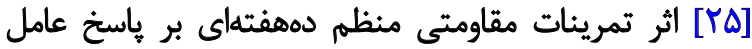

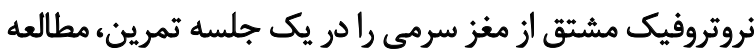

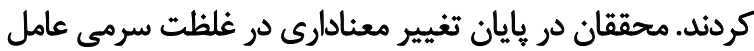

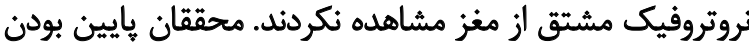

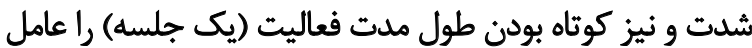

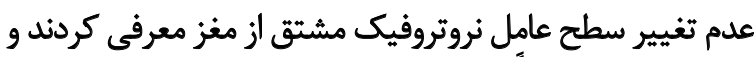

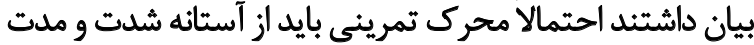

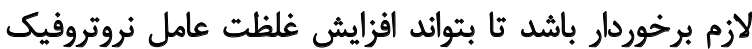
مشتق از مغز را به دنبال داشته باشد.

كوريا و همكاران [\&ץ] به بررسى اثر تمرينات مقاومتى حاد

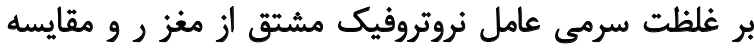

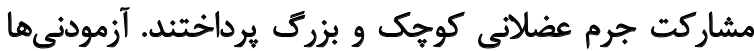

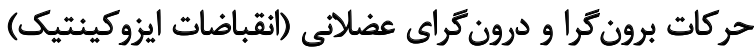

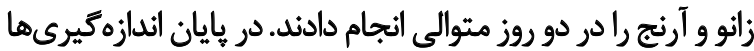

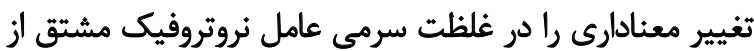

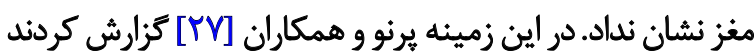

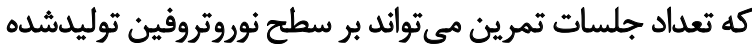

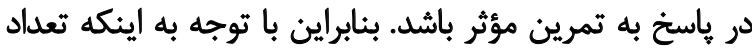

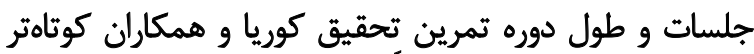

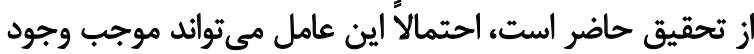
اختثلاف باشد.
نتايج جدول شماره f حاكى از اين است كه تمرينات تركيبى

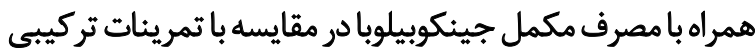

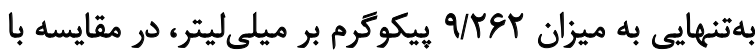

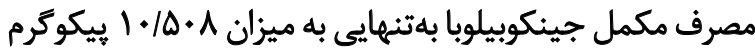

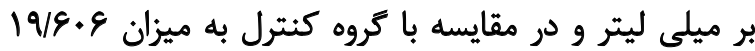

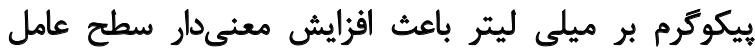

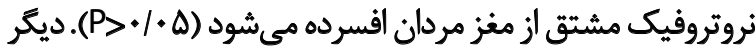

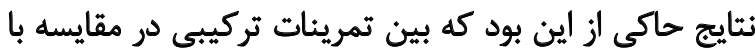

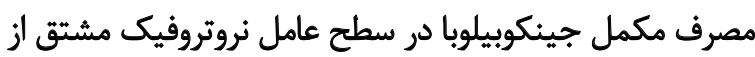

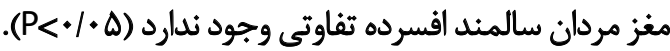

ثب

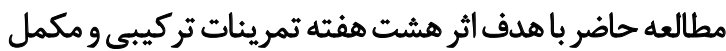

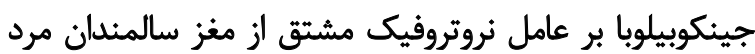

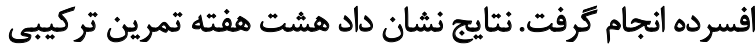

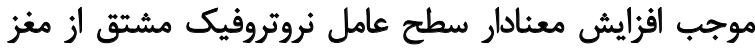

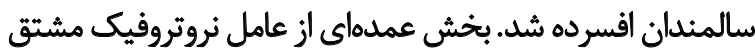

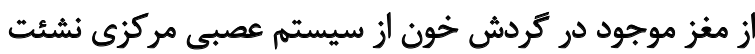

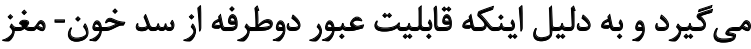

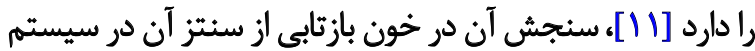

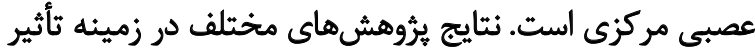

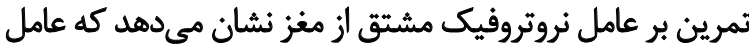

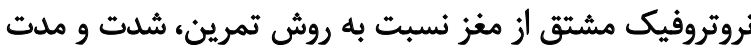

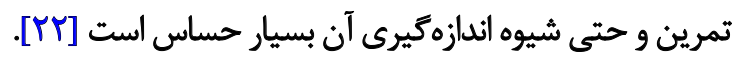
در اين زمينه شريفى و همكاران [آ] نشان دادند كه هشت

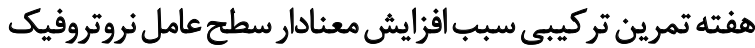

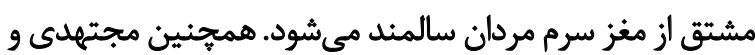

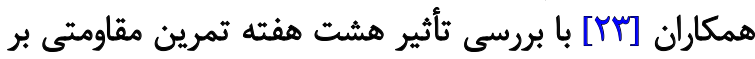

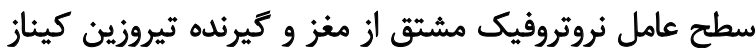

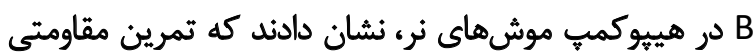

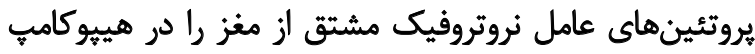


همجنين نُشان دادند كه اين افزايش حجم همراستا با افزايش

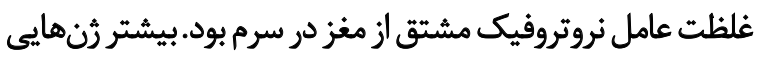

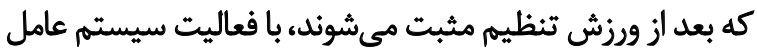

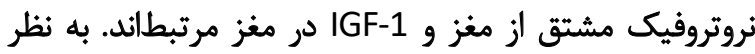

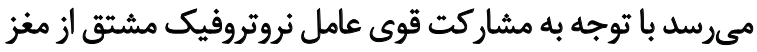

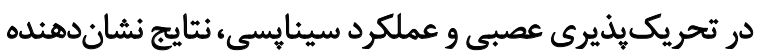

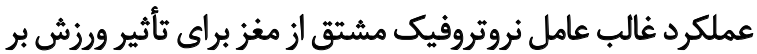

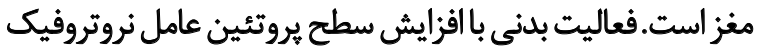

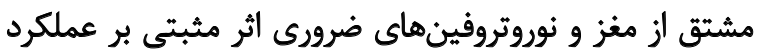

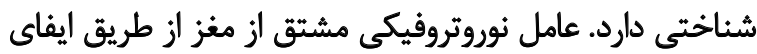

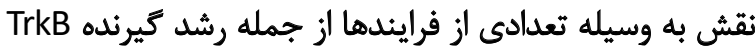

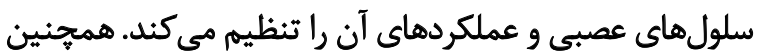

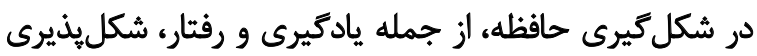

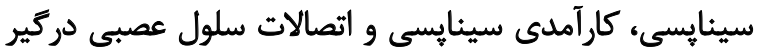

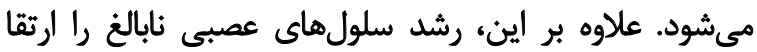

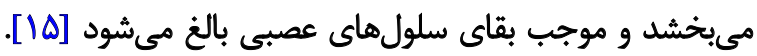

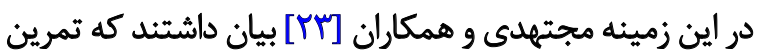

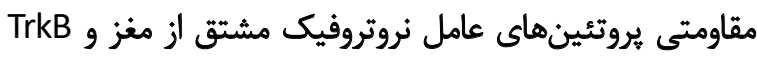

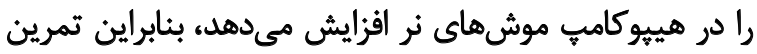

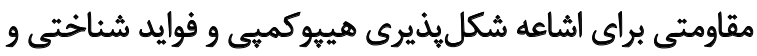

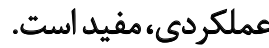

ديكر نتايج تحقيق حاضر نشان داد كه مصرف مكمل

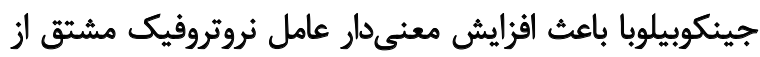

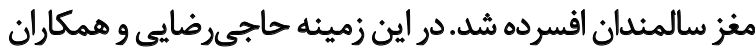

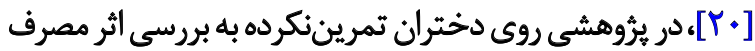

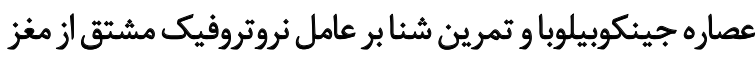

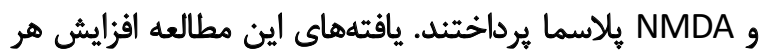

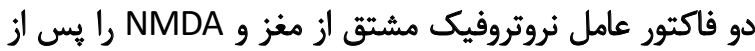

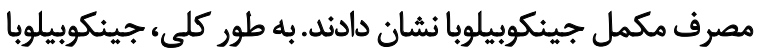

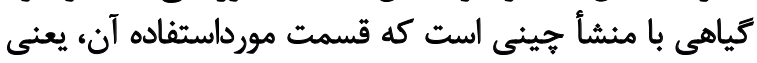

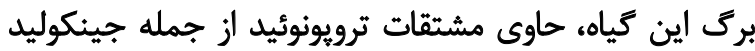

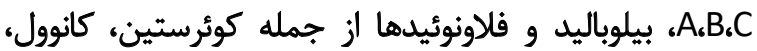

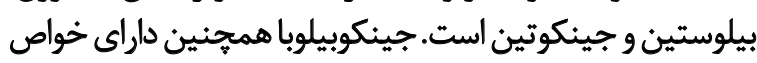

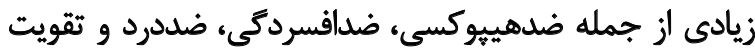

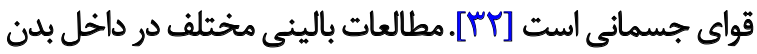

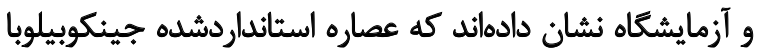

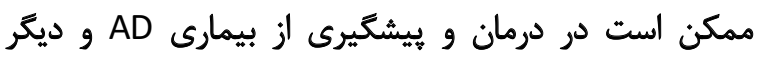

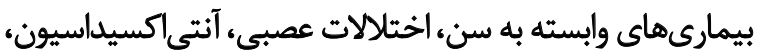

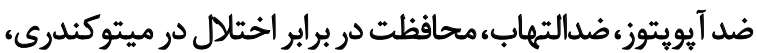

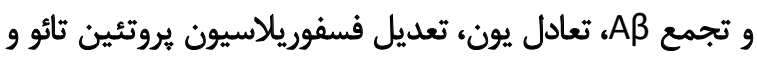

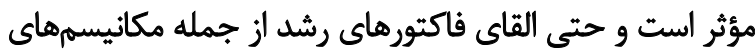

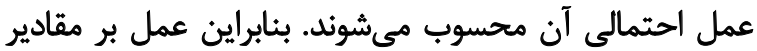

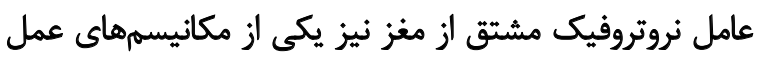

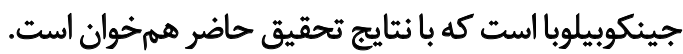

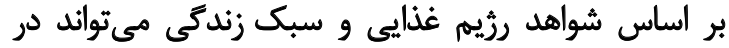

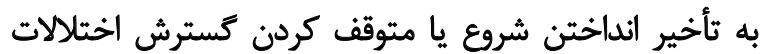

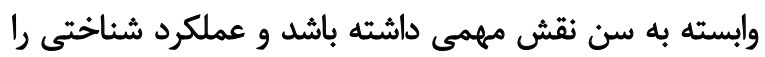
بهبود بخشد. در سالهاي اخير توجه محققان بهان به تأثير فعاليت

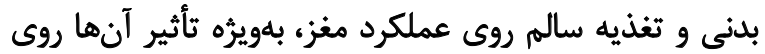

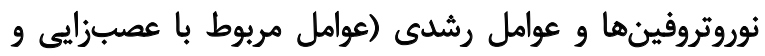

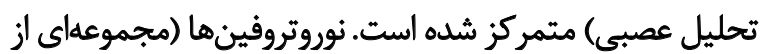

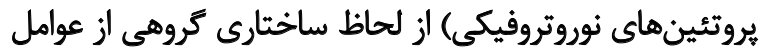

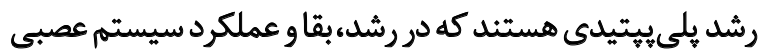

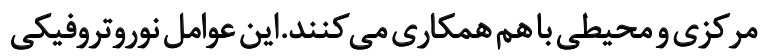

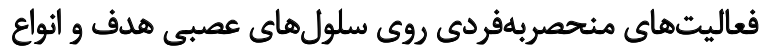

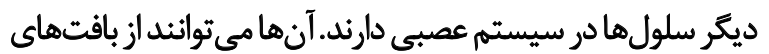

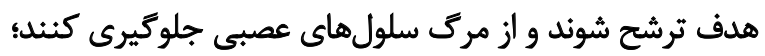

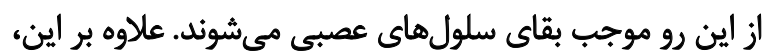

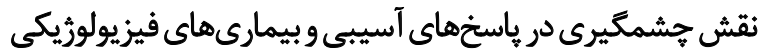

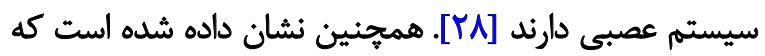

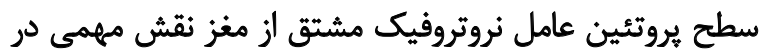

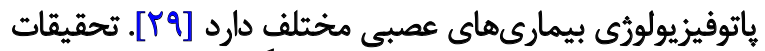

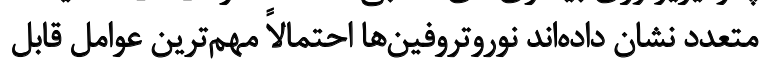

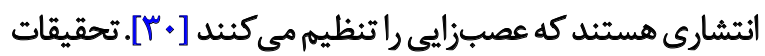

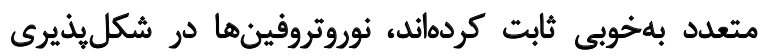

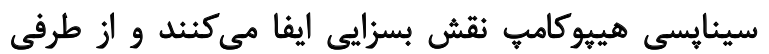

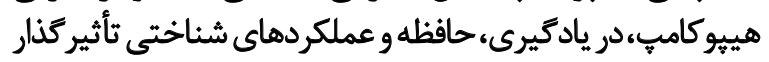

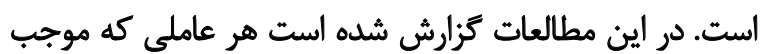

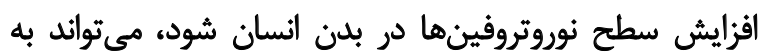

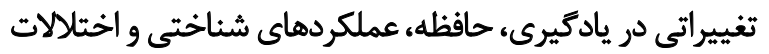

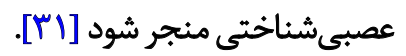

كوريه و همكاران [عץ] ارتباط بين عامل نروتروفيك مشتق

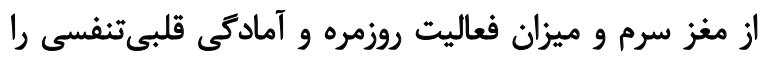

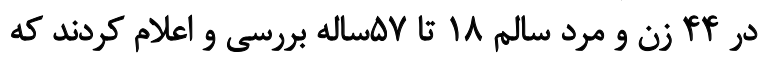

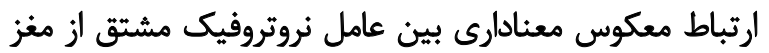

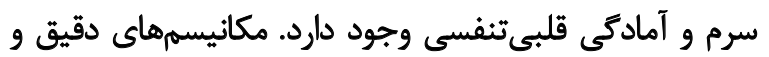

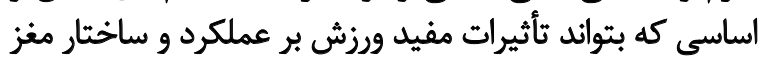

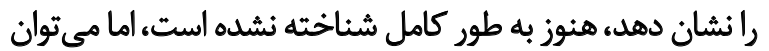

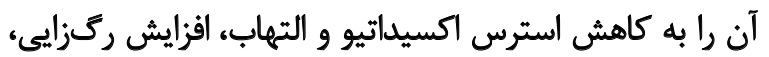

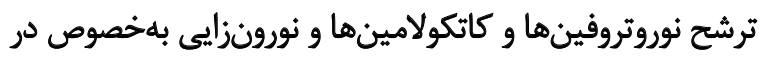

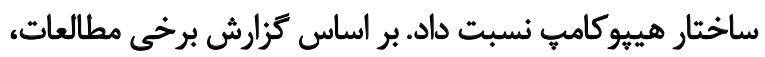

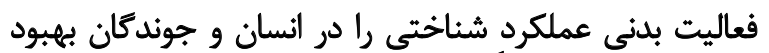

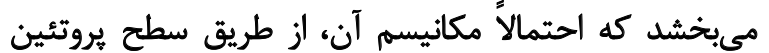

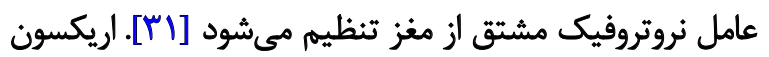

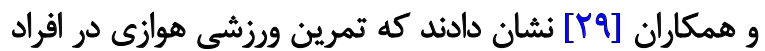

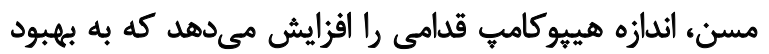

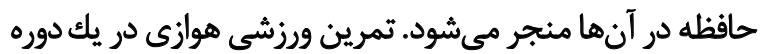

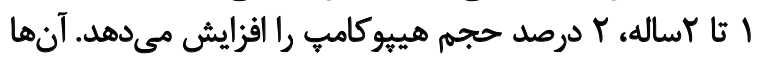


با توجه به نتايج مطالعه حاضر بيشنهاد مىشود كه سالمندان

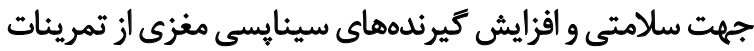

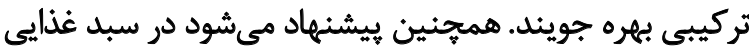

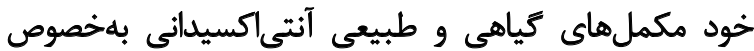

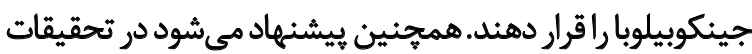

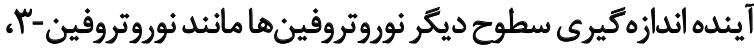

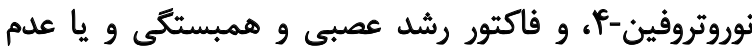

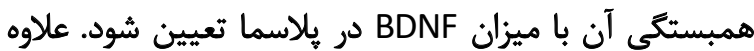

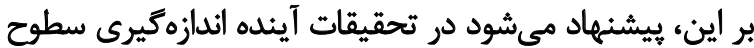

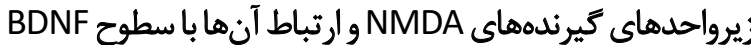

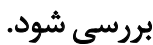

مالاحظات اخلاقي

\section{ي بيروى ازٔ اصول الخلاق يثوهش}

اصول اخلاقى تماماً در اين مقاله رعايت شده است. شركت

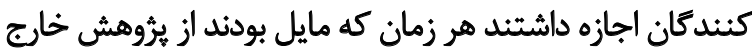

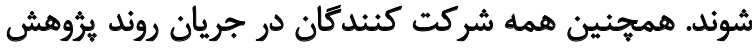
بودند. اطلاعات آن ها محرمانه نكَه داشته شد شد.

$$
\text { مامي مالى }
$$

اين تحقيق هيج كونه كمك مالى از سازمانهاي تأمين مالى در

بخشهاى عمومى ، تجارى يا غيرائتفاعى دريافت نكرد.

$$
\text { مشاركت ثويسند }
$$

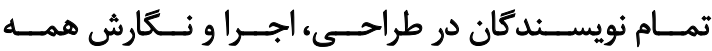

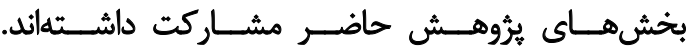

ت تعارض مثاقع

بنابر اظهار نويسندكان اين مقاله تعارض منافع ندارد.
ديكر نتايج تحقيق حاضر نشان داد كه تمرين تركيبى همراه

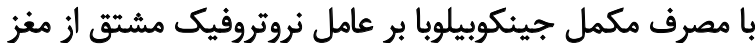

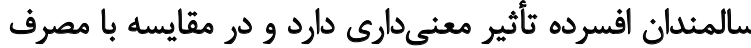

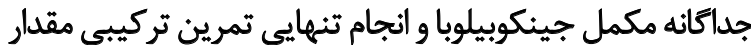

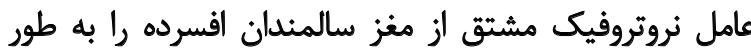

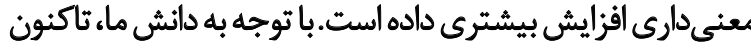

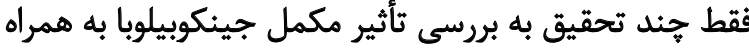

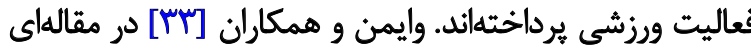

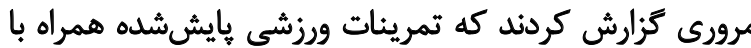

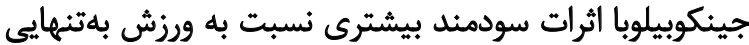

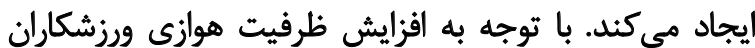

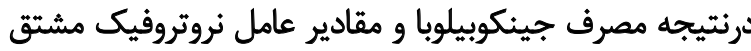

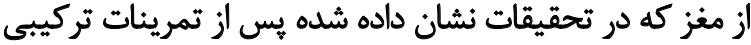

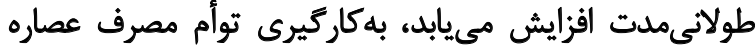

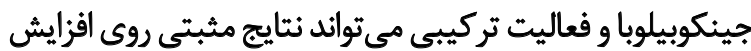

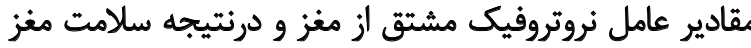

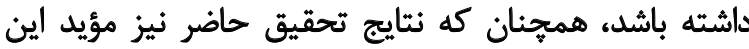

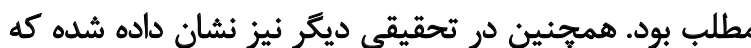

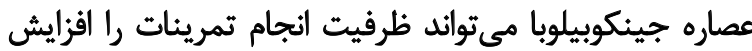

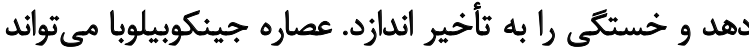

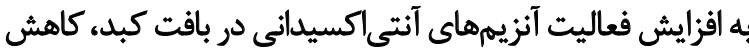

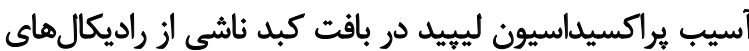

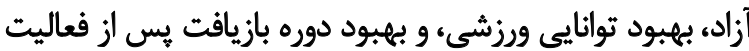

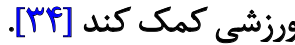

\section{تئيجه كيرى نهايي}

اجراى تمرينات تركيبى به مدت هشت هفته به همراه مكمل بروب

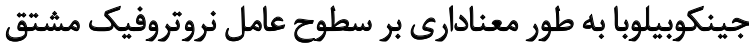

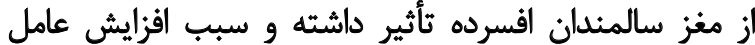

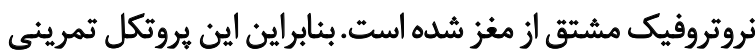

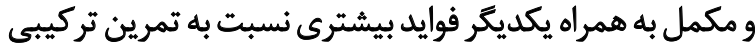

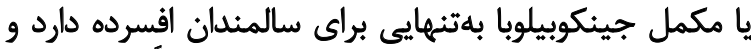

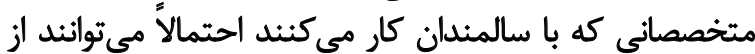

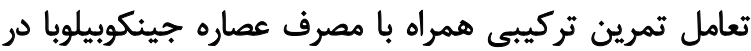
بهبود ظرفيت عملكردى مغز استفاده كنيند. تمكري

عدم كنترل دقيق مصرف دارو ياغذاى خاص توسط آزمودنى هارها

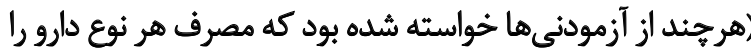

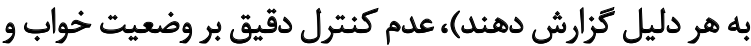

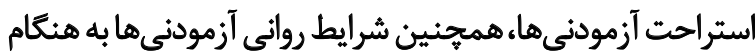

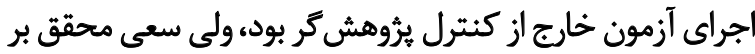

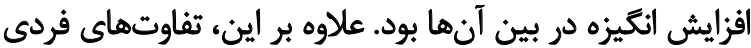

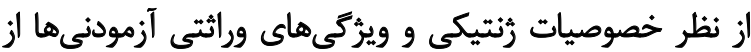

محدوديتهاى تحقيق حاضر بود. 


\section{References}

[1] Alipour F, Sajadi H, Forouzan A, Biglarian A, Jalilian A. [Elderly quality of life in Tehran's district two (Persian)]. Salmand: Iranian Journal of Ageing. 2008;3(3-4):75-83. http:/ / salmandj.uswr.ac.ir/ article-1-104-en.html

[2] Sharifzadeh GR, Moodi M, Akhbari H. [Investigating health status of older people supported by Imam (Persian)]. Salmand: Iranian Journal of Ageing. 2010; 5(3):52-60. http:// salmandj.uswr. ac.ir/article-1-279-en.html

[3] Hojjati H, Koochaki G, Sanagoo A. [The relationship between loneliness and life satisfaction of the elderly in Gorgan and Gonbad cities (Persian)]. Journal of Research Development in Nursing and Midwifery. 2012; 9(1):61-8. http://nmj.goums.ac.ir/article1-213-en.html

[4] Khodadady N, Sheikholeslami F, Rezamasuoleh S, Yazdani M. [Rate of depression in late-life in superannuated government employed center of Guilan University of Medical Sciences (Persian)]. Journal of Holistic Nursing And Midwifery. 2007; 17(1):16-22. http://hnmj.gums.ac.ir/article-1-247-en.html

[5] Sajadi H, Mohaqeqi Kamal H, Vameghi M, Forozan AS, Rafei H, Nosratabadi M. [Systematic review of prevalence and risk factors associated with depression and its treatment in Iranian elderly (Persian)]. Salmand: Iranian Journal of Ageing. 2013; 7(4):7-15. http://salmandj.uswr.ac.ir/article-1-545-en.html

[6] Lai DWL. Impact of culture on depressive symptoms of elderly Chinese immigrants. The Canadian Journal of Psychiatry. 2004; 49(12):820-7. [DOI:10.1177/070674370404901205]

[7] Cole MG, Dendukuri N. Risk factors for depression among elderly community subjects: A systematic review and metaanalysis. American Journal of Psychiatry. 2003; 160(6):1147-56. [DOI:10.1176/appi.ajp.160.6.1147]

[8] Adlard PA, Cotman CW. Voluntary exercise protects against stress-induced decreases in brain-derived neurotrophic factor protein expression. Neuroscience. 2004; 124(4):985-92. [DOI:10.1016/j.neuroscience.2003.12.039]

[9] Fujimura H, Altar CA, Chen R, Nakamura T, Nakahashi T, Kambayashi JI, et al. Brain-derived neurotrophic factor is stored in human platelets and released by agonist stimulation. Thrombosis and Haemostasis. 2002; 87(04):728-34. [DOI:10.1055/s-0037-1613072]

[10] Pan W, Banks WA, Fasold MB, Bluth J, Kastin AJ. Transport of brain-derived neurotrophic factor across the blood-brain barrier. Neuropharmacology. 1998; 37(12):1553-61. [DOI:10.1016/S00283908(98)00141-5]

[11] Ploughman M. Exercise is brain food: The effects of physical activity on cognitive function. Developmental Neurorehabilitation. 2008; 11(3):236-40. [DOI:10.1080/17518420801997007]

[12] Xu B, Goulding EH, Zang K, Cepoi D, Cone RD, Jones KR, et al. Brain-derived neurotrophic factor regulates energy balance downstream of melanocortin-4 receptor. Nature Neuroscience. 2003; 6(7):736-42. [DOI:10.1038/nn1073]

[13] Tsuchida A, Nonomura T, Nakagawa T, Itakura Y, OnoKishino M, Yamanaka $M$, et al. Brain-derived neurotrophic factor ameliorates lipid metabolism in diabetic mice. Diabetes, Obesity and Metabolism. 2002; 4(4):262-9. [DOI:10.1046/j.14631326.2002.00206.x]

[14] Knaepen K, Goekint M, Heyman EM, Meeusen R. Neuroplasticity - exercise-induced response of peripheral brain-de- rived neurotrophic factor. Sports Medicine. 2010; 40(9):765-801. [DOI:10.2165/11534530-000000000-00000]

[15] Zoladz JA, Pilc A. The effect of physical activity on the brain derived neurotrophic factor: From animal to human studies. Journal of Physiology and Pharmacology. 2010; 61(5):533-41. [PMID]

[16] Nofuji Y, Suwa M, Moriyama Y, Nakano H, Ichimiya A, Nishichi $R$, et al. Decreased serum brain-derived neurotrophic factor in trained men. Neuroscience Letters. 2008; 437(1):29-32. [DOI:10.1016/j.neulet.2008.03.057]

[17] Dubber MJ, Kanfer I. Determination of terpene trilactones in Ginkgo biloba solid oral dosage forms using HPLC with evaporative light scattering detection. Journal of Pharmaceutical and Biomedical Analysis. 2006; 41(1):135-40. [DOI:10.1016/j. jpba.2005.11.010]

[18] Gardner CD, Taylor-Piliae RE, Kiazand A, Nicholus J, Rigby AJ, Farquhar JW. Effect of Ginkgo biloba (EGb 761) on treadmill walking time among adults with peripheral artery disease: A randomized clinical trial. Journal of Cardiopulmonary Rehabilitation and Prevention. 2008; 28(4):258-65. [DOI:10.1097/01. HCR.0000327184.51992.b8]

[19] Bing Y, Zhaobao W. Effects of Ginkgo biloba extract on free radical metabolism of liver in mice during endurance metabolism. African Journal of Traditional, Complementary and Alternative Medicines. 2010; 7(4):291-5. [DOI:10.4314/ajtcam.v7i4.56691]

[20] Hajirezaii B, Barari A, Abbassi Daloii A. [Consumption of Ginkgo biloba extract and swimming training on NMDA and BDNF plasma in untrained girls (Persian)]. Journal of Medicinal Plants. 2015; 14(54):183-90. http://jmp.ir/article-1-1020-fa.html

[21] Sharifi GR, Bani Hashemi Emam Gheysi M, Rahnama N, Babai Mazrae No AR. [Comparison of the effect of 8 weeks aerobic exercise with resistance exercise on brain-derived neurotrophic factor in elderly men (Persian)]. Salmand: Iranian Journal of Ageing. 2015; 10(3):148-55. http://salmandj.uswr.ac.ir/article-1-814-en. $\mathrm{html}$

[22] Ravasi AS, Poornemati P, Kordi MR, Hedayati M. [The effect of two type of resistance and endurance exercise on BDNF and cortisol of young male mice (Persian)]. Journal of Sport Biosciences. 2013; 1(16):49-78. [DOI:10.22059/JSB.2013.30458]

[23] Mojtahedi S, Shabkhiz F, Akbarnejad A, Salehian O. [Effect of 8 weeks resistance training on BDNF and TrkB in the hippocampus of adult male rats (Persian)]. Armaghane Danesh. 2014; 19(5):3809. http://armaghanj.yums.ac.ir/article-1-173-en.html

[24] Yarrow JF, White LJ, McCoy SC, Borst SE. Training augments resistance exercise induced elevation of circulating Brain Derived Neurotrophic Factor (BDNF). Neuroscience Letters. 2010; 479(2):161-5. [DOI:10.1016/j.neulet.2010.05.058]

[25] Goekint M, De Pauw K, Roelands B, Njemini R, Bautmans I, Mets $T$, et al. Strength training does not influence serum brainderived neurotrophic factor. European Journal of Applied Physiology. 2010; 110(2):285-93. [DOI:10.1007/s00421-010-1461-3]

[26] Correia PR, Pansani A, Machado F, Andrade M, da Silva AC, Scorza FA, et al. Acute strength exercise and the involvement of small or large muscle mass on plasma brain-derived neurotrophic factor levels. Clinics. 2010; 65(11):1123-6. [DOI:10.1590/S180759322010001100012]

[27] Parnow A, Karimi I, Hosseini SA. [Effect of resistance training on plasma brain derived neurotrophic factor levels in rats 
(Persian)]. Journal of Knowledge \& Health. 2015; 10(3):9-14. [DOI:10.22100/jkh.v10i3.679]

[28] Twiss JL, Chang JH, Schanen NC. Pathophysiological mechanisms for actions of the neurotrophins. Brain Pathology. 2006; 16(4):320-32. [DOI:10.1111/j.1750-3639.2006.00039.x]

[29] Erickson KI, Voss MW, Prakash RS, Basak Ch, Szabo A, Chaddock L, et al. Exercise training increases size of hippocampus and improves memory. Proceedings of the National Academy of Sciences. 2011; 108(7):3017-22. [DOI:10.1073/pnas.1015950108]

[30] Lu B, Chang JH. Regulation of neurogenesis by neurotrophins: Implications in hippocampus-dependent memory. Neuron Glia Biology. 2004; 1(4):377-84. [DOI:10.1017/S1740925X05000232]

[31] Griffin ÉW, Mullally S, Foley C, Warmington SA, O'Mara SM, Kelly ÁM. Aerobic exercise improves hippocampal function and increases BDNF in the serum of young adult males. Physiology \& Behavior. 2011; 104(5):934-41. [DOI:10.1016/j.physbeh.2011.06.005

[32] Savaskan E, Mueller H, Hoerr R, von Gunten A, Gauthier S. Treatment effects of Ginkgo biloba extract EGb 761® on the spectrum of behavioral and psychological symptoms of dementia: Meta-analysis of randomized controlled trials. International Psychogeriatrics. 2018; 30(3):285-93. [DOI:10.1017/S1041610217001892]

[33] Weinmann S, Roll S, Schwarzbach Ch, Vauth Ch, Willich SN. Effects of Ginkgo biloba in dementia: Systematic review and meta-analysis. BMC Geriatrics. 2010; 10:14. [DOI:10.1186/14712318-10-14]

[34] Herrschaft H, Nacu A, Likhachev S, Sholomov I, Hoerr R, Schlaefke S. Ginkgo biloba extract EGb $761^{\circledR}$ in dementia with neuropsychiatric features: A randomised, placebo-controlled trial to confirm the efficacy and safety of a daily dose of $240 \mathrm{mg}$. Journal of Psychiatric Research. 2012; 46(6):716-23. [DOI:10.1016/j. jpsychires.2012.03.003] 
This Page Intentionally Left Blank 